\title{
8 Research Square

\section{Exposure Characteristics of Phthalate Metabolites Among The Zunyi Cohort of Pregnant Women in Southwest China}

\section{Juan Liao (D 630140512@qq.com)}

Soochow University Medical College https://orcid.org/0000-0002-3799-2272

\section{Derong Fang}

Affiliated Hospital of Zunyi Medical University

Yijun Liu

Zunyi Medical University

\section{Shimin Xiong}

Zunyi Medical University

Xia Wang

Zunyi Medical University

Yingkuan Tian

Zunyi Medical University

\section{Haonan Zhang}

Zunyi Medical University

\section{Songlin An}

Zunyi Medical University

Caidie He

Zunyi Medical University

\section{Wei Chen}

Zunyi Medical University

\section{Xiang Liu}

Zunyi Medical University

Nian Wu

Zunyi Medical University

\section{Kunming Tian}

Zunyi Medical University

\section{Linglu Wang}

The Second Affiliated Hospital of Zunyi Medical University

\section{Ya Zhang}

Zunyi Medical University

Hongyu Yuan

Zunyi Medical University

Li Zhang

Zunyi Medical University

\section{Quan Li}

Affiliated Hospital of Zunyi Medical University

\section{Xubo Shen}

Zunyi Medical University

Yuanzhong Zhou

Zunyi Medical University

\section{Research Article}

Keywords: phthalate, pregnancy, urinary metabolites, exposure levels, sampling season, detectable rate

Posted Date: February 3rd, 2022 
DOI: https://doi.org/10.21203/rs.3.rs-1190081/v1

License: (a) (4) This work is licensed under a Creative Commons Attribution 4.0 International License. Read Full License 


\section{Abstract}

Reported evidence has increasingly indicated that exposure to phthalates can cause adverse pregnancy outcomes. However, phthalate exposure levels among pregnant women remains unclear. We aimed to evaluate the concentrations of phthalate metabolites in urine samples of the Zunyi cohort of pregnant women from Southwest China. The study was conducted between August 2020 and July 2021, and urine samples were collected from 1003 pregnant women during their third trimester of pregnancy. The concentrations of nine phthalate metabolites in urine samples were then determined. Data on socio-demographic profiles of the participants, lifestyle during pregnancy, parity, and sampling season were collected using questionnaires. The detectable rate of phthalate metabolites ranged from $76-100 \%$. On average, mono-butyl phthalate exhibited the highest median concentration $(84.24 \mu \mathrm{g} / \mathrm{L})$, while mono-benzyl phthalate exhibited the lowest median concentration $(0.08 \mu \mathrm{g} / \mathrm{L})$. Urine concentrations of phthalate metabolites were significantly higher in older, multiparous, higher-body mass index, higher-income, and passive-smoking during pregnancy participants. The levels of low-molecular-weight phthalate metabolites were highest during the summer. In light of our findings, phthalate metabolites present a demographic and seasonal differential distribution among the study population.

\section{Introduction}

Phthalates are widely used in numerous consumer and food packaging products, resulting in the inevitable long-term exposure of the human body to phthalate metabolites (Benjamin et al., 2017; Calafat et al., 2015). The results of previously published studies suggest that some of these metabolites may adversely impact human health, particularly during sensitive periods of life, such as in utero (Ipapo et al., 2017; Bergman et al., 2013).

Published epidemiological data suggest that maternal prenatal exposure to phthalate metabolites endanger maternal and fetal health as well as birth outcomes. A prospective cohort study conducted in Denmark (Toft et al., 2012) found that the concentration of mono(2-ethylhexyl) phthalate (DEHP) in pregnant women's urine before pregnancy was correlated with the risk of spontaneous abortions. Several studies in United States (Messerlian et al., 2016) and China (Mu et al., 2015; Liao et al., 2018; Gao et al., 2017) have reached the same conclusion. Additionally, maternal exposure to phthalates can increase the odds of preterm birth (Ferguson et al., 2019; Broe et al., 2019; Gao et al., 2019), and it is related to fetal birth size (Guo et al., 2020; Polańska et al., 2016; De et al., 2015). Moreover, maternal exposure to phthalates was observed to lead to gestational hypertension and gestational diabetes mellitus (Werner et al., 2015; James-Todd et al., 2016). Finally, in vivo (Chen et al., 2020) and in vitro experimental studies (Zong et al., 2015) have reached the same conclusions as the population studies. Chen et al. found that exposure to din-butyl phthalate (DBP) during pregnancy promotes the insurgence of gestational diabetes mellitus by significantly increasing the expression of protein pSTAT1 and inhibiting that of FOXM1; the authors also found that the said exposure causes a decrease in islets $\beta$ cell viability (Chen et al., 2020). Zong proposed that, in mice, exposure to DEHP during pregnancy administration disrupted labyrinth vascularization of placentas, and inhibited proliferation and induced apoptosis of placenta by the activation of caspase-3 and caspase-8, up-regulation of Bax and downregulation of Bcl-2 mRNA and protein resulting in an increase in the probability of embryonic loss and a decrease in fetal body weight (Zong et al., 2015).

Given the hazards to maternal and infant health associated with the exposure to phthalate metabolites, it is necessary to determine the exposure levels of phthalate metabolites in pregnant women and analyze the risk factors leading to that exposure. As described in the literature, following exposure to phthalates present in a variety of sources, such as water, air, soil, and food, these chemicals enter the human body through ingestion, inhalation, or dermal exposure (Dualde et al., 2020); as a result, different exposure routes and sources may be associated with different exposure levels for the human population. Previously published studies have discussed the distribution and predictors of the presence of phthalate metabolites in the urine of pregnant women in Eastern China (He et al., 2019; Gao et al., 2017) and other developed countries (Polinski et al., 2018; Wenzel et al., 2018; Wu et al., 2020). These population surveys conducted in economically developed geographical areas indicate that the exposure level of phthalates in pregnant women's urine is related to economic conditions, education, race, age, body mass index (BMI), dietary patterns, and lifestyle. Nevertheless, data on the level of phthalate pollution in areas characterized by underdeveloped economies, good ecological environmental protection, and relatively small chemical pollution are still missing, leading to no comprehensive assessment of maternal-fetal harm of phthalate metabolites.

Therefore, the goal of the present investigation was to conduct a population-based study aimed at determining the level of phthalate metabolites in pregnant women from undeveloped Southwest China as well as the correlation of this parameter with demographic characteristics and seasonal variations. The results of such a study could offer suggestions on suitable specific interventions to reduce the risk of high phthalate exposure during pregnancy.

\section{Methods}

\section{Study population}


Pregnant women hospitalized for childbirth in the third trimester were recruited from August 2020 to July 2021 at Xishui and Meitan County People's Hospital, which are located in Zunyi city, Southwest China. After informed consent, study participants signed the informed consent form and filled in the electronic questionnaire during face-to-face interviews. Study eligibility criteria included natural conception, singleton pregnancy, and live fetus. Patients were excluded if they were suffering from serious chronic diseases and infectious diseases, such as cancer, chronic cardiovascular and cerebrovascular diseases, chronic renal failure, and HIV infection. This study was ethically reviewed by the Affiliated Hospital of Zunyi Medical University (batch No.: KLL-2019-006).

\section{Survey questionnaire}

The questions to include in the questionnaire were discussed and decided by several epidemiological experts over many meetings. Demographic information was obtained through a questionnaire administered to women upon enrollment in the study; the questionnaire included queries on the demographic data of pregnant women: age, pre-pregnancy weight, height, education, annual household income, lifestyle during pregnancy (smoking, drinking, passive smoking, and drinking bottled water), parity, and sampling season. The participants' BMI (weight (kg)/height (m) ${ }^{2}$ ) was calculated based on physician-recorded height and weight at the time of enrollment. Based on maternal age, participants were divided into the following three groups: $<25$ years, 25-29 years, and $\geq 30$ years of age. Based on pre-pregnancy BMI, participants were divided into the following three groups: underweight $\left(<18.5 \mathrm{~kg} / \mathrm{m}^{2}\right)$, normal $\left(18.5-23.9 \mathrm{~kg} / \mathrm{m}^{2}\right)$, and overweight $\left(\geq 24 \mathrm{~kg} / \mathrm{m}^{2}\right)$. Participants were divided into four groups based on annual household income: low income $(<¥ 100,000)$, middle income $(¥ 100,000-¥ 150,000)$, high income (> $¥ 150,000)$, and don’t know. Based on maximum education level reached, participants were divided into three ordinal groups: middle school or below, high school and middle special school, college degree or above. Parity afforded the definition of two participant groups: nulliparous (0) and multiparous ( $\geq 1$ ). Passive smoking is defined as exposure to cigarette smoke for at least half an hour a day. The sampling seasons were defined as follows: spring (March-May), summer (June-August), fall (September-November), and winter (December-February). Maternal age and BMI were treated as continuous variables, and annual household income, maternal education, passive smoking, parity, drinking bottled water, and sample collection season were treated as categorical variables.

\section{Measurement of phthalate metabolites}

Urine samples from 1003 women were analyzed to determine the concentration of nine phthalate metabolites by high-performance gas chromatography mass spectrometry (GC-MS/MS, Agilent 7010b, Santa Clara, CA, USA); these metabolites are mono-methyl phthalate (MMP), mono-methyl phthalate (MEP), mono-ethyl phthalate (MiBP), mono-butyl phthalate (MBP), mono-octyl phthalate (MOP), mono-benzyl phthalate (MBzP), mono(2-ethylhexyl) phthalate (MEHP), mono(2-ethyl-5-oxohexyl) phthalate (MEOHP), and mono(2-ethyl-5-hydroxyhexyl) phthalate (MEHHP). Spot urine specimens were collected in polypropylene tubes in the obstetrical clinics and transferred to the Zunyi Medical University Laboratory (Zunyi, Southwest China) for analysis; urine samples were divided into $1-\mathrm{mL}$ aliquots and stored at $-80{ }^{\circ} \mathrm{C}$ until analysis. Urinary creatinine concentration was determined by the laboratory of the Affiliated Hospital of Zunyi Medical University using an automatic urine analyzer (Beckman, AU5800, Kraemer Boulevard Brea, CA, USA). Details of the method for detecting the concentration of metabolites in urine can be found in the Supplementary information. Briefly, $1.5 \mathrm{~mL}$ of urine were added into a $10 \mathrm{~mL}$ centrifuge tube $\$ add $1 \mathrm{~mL}$ of sodium acetate solution buffer to urine sample and standard sample, $10 \mu \mathrm{L}$ internal standard solution and $10 \mu \mathrm{L} \beta$-glucuronidase/sulphatase enzyme to fully hydrolyze the sample; excess $\mathrm{MgSO}_{4} \cdot 7 \mathrm{H}_{2} \mathrm{O}$ was then added to reach solution supersaturation. To the tubes was then added $1 \mathrm{~mL}$ of $\mathrm{n}$-hexane + diethyl ether ( $4: 1)$; the tubes were then centrifuged, and the relevant supernatants were transferred to new 5 -mL centrifuge tubes; this step was repeated twice and blow dry twice with nitrogen; the silylation reagent [N. O-bis (trimethylsilane) trifluoroacetamide: trimethylchlorosilane=99:1] was then added to the 5-mL centrifuge tubes containing the supernatants; after the complete derivatization and analyze them after allowing the bottle to cool to $37^{\circ} \mathrm{C}$.

\section{Statistical analyses}

The limit of detection (LOD) of phthalate metabolites were assumed to correspond numerically to three times the signal-to-noise ratio; therefore, the LOD values for MMP, MEP, MiBP, MBP, MOP, MBZP, MEOHP, MEHHP, and MEHP were determined to be 0.038, 0.029, 0.002, 0.002, 0.063, 0.041, $1.071,0.010$, and $0.033 \mu \mathrm{g} / \mathrm{L}$, respectively; notably, in our analyses, we replaced the phthalate metabolite concentrations that were below the LOD with the relevant LOD value divided by the square root of 2 . The total concentration of low-molecular-weight (LMW) phthalates ( $\Sigma L M W)$ was calculated as the total sum of the molar concentrations of the three metabolites (MMP, MEP and MBP), and the formula is $\Sigma L M W(n m o l / L)=$ [MMP $(\mu \mathrm{g} / \mathrm{L}) / 180+\mathrm{MEP}(\mu \mathrm{g} / \mathrm{L}) / 194+\mathrm{MBP}(\mu \mathrm{g} / \mathrm{L}) / 222] \times 1000$. The total concentration of DEHP $\left(\sum \mathrm{DEHP}\right)$ was calculated as the total sum of the molar concentrations of the three metabolites (MEHP, MEOHP and MEHHP), and the formula is $\sum \mathrm{DEHP}(\mathrm{nmol} / \mathrm{L})=$ $[\mathrm{MEHP}(\mu \mathrm{g} / \mathrm{L}) / 278+\mathrm{MEOHP}(\mu \mathrm{g} / \mathrm{L}) / 294+\operatorname{MEOHP}(\mu \mathrm{g} / \mathrm{L}) / 292] \times 1000$. Urine creatinine concentration was used to correct for urine dilution employing to the following formula: urine creatinine-corrected phthalate metabolite concentration $(\mathrm{mg} / \mathrm{g}$ crea $)=\mathrm{phthalate}$ metabolite concentration $(\mathrm{mg} / \mathrm{L}) /$ [urine creatinine concentration $\left.(\mathrm{mg} / \mathrm{L}) \times 113(\mathrm{~g} / \mathrm{mol}) \times 10^{-6}\right]$. Notably, we calculated both the unadjusted and creatinineadjusted urine phthalate metabolite concentration distributions (geometric mean and percentile values). The distributions of nine phthalate metabolites as well as $\Sigma \mathrm{LMW}$ and $\Sigma \mathrm{DEHP}$ were skewed, thus we performed the natural logarithm transformation(In) of creatinine-adjusted phthalate metabolite concentrations to produce more normal distributions for statistical analyses. Multivariable linear regression was employed 
to determine the relationship between demographic variable category and season and metabolite concentrations corrected for urinary creatinine. Finally, Spearman's rank correlation coefficient was used to test the correlation between different phthalate metabolite concentrations. All analyses were performed with SPSS version 25.0 (IBM Corp. Armonk, NY, USA); the applied threshold for statistical significance was $\mathrm{p} \otimes 0.05$ (two-tailed).

\section{Results}

\section{Basic demographic characteristics}

The basic demographic characteristics of the overall population are presented in Table 1 . The average age was $26.7 \pm 5.0$ years old, and the age group comprising the largest proportion of participants (40.4\%) was the 25-29 years old category. The average pre-pregnancy BMI value was $22.4 \pm 3.5 \mathrm{~kg} / \mathrm{m}^{2}$, and the BMl category comprising the largest proportion of participants (61.3\%) was the normal weight group. Moreover, $59.4 \%$ of participants had an education level of middle school or below, $58 \%$ came from households in the annual middle-income bracket, and multiparous participants accounted for $60.4 \%$ of the cohort. In this study, none of the participants smoked or drank alcohol during pregnancy, but $11.7 \%$ were categorized as passive smokers. Approximately $7.6 \%$ of participants drank bottled water during pregnancy. The highest proportion of participants was enrolled in the study during the winter (44\%), while the lowest proportion was enrolled during the summer (7.5\%).

Table 1. Characteristics of study subjects $(\mathrm{N}=1003)$ in the study. 


\begin{tabular}{|c|c|}
\hline Characteristics & Mean \pm SD or $n(\%)$ \\
\hline Maternal age at delivery (years) & $26.7 \pm 5.0$ \\
\hline$\nabla 25$ & $342(34.1)$ \\
\hline $25-29$ & $405(40.4)$ \\
\hline$\geq 30$ & $256(25.5)$ \\
\hline Pre-pregnancy BMI $\left(\mathrm{kg} / \mathrm{m}^{2}\right)$ & $22.4 \pm 3.5$ \\
\hline Underweight (ه18.5) & $105(10.5)$ \\
\hline Normal weight (18.5-23.9) & $615(61.3)$ \\
\hline Overweight $(\geq 24)$ & $283(28.2)$ \\
\hline \multicolumn{2}{|l|}{ Annual household income (Yuan) } \\
\hline$\nabla 100000$ & 174(17.4) \\
\hline $100000-150000$ & $582(58.0)$ \\
\hline$\geq 150000$ & $231(23.0)$ \\
\hline Don't know & $16(16.0)$ \\
\hline \multicolumn{2}{|l|}{ Education } \\
\hline middle school or below & $596(59.4)$ \\
\hline High school and middle special school & $266(26.5)$ \\
\hline College degree or above & $141(14.1)$ \\
\hline \multicolumn{2}{|l|}{ Parity } \\
\hline Nulliparous & $397(39.6)$ \\
\hline Multiparous & $606(60.4)$ \\
\hline \multicolumn{2}{|l|}{ Passive smoking } \\
\hline Yes & $117(11.7)$ \\
\hline No & $886(88.3)$ \\
\hline \multicolumn{2}{|l|}{ Drinking bottled water } \\
\hline Yes & $927(92.4)$ \\
\hline No & $76(7.6)$ \\
\hline \multicolumn{2}{|l|}{ Sample collection season } \\
\hline Spring & $255(25.4)$ \\
\hline Summer & $75(7.5)$ \\
\hline Fall & $232(23.1)$ \\
\hline Winter & $441(44.0)$ \\
\hline
\end{tabular}

Abbreviations: BMI, body mass index; SD, standard deviation.

\section{Phthalate metabolite distribution}

The values for the detectable rate, geometric mean, and the quartile of both unadjusted and creatinine-adjusted concentrations of phthalate metabolites are listed in Table 2. The detectable rates of the phthalate metabolites MMP, MEP, MiBP, MBP, MOP, MBZP, MEHP, MEOHP, and MEHHP in participants' urine samples were 76\%, 97.8\%, 99.6\%, 100\%, 87.1\%, 77.5\%, 93.7\%, 87.4\%, and 93.7\%, respectively. On average, MBP exhibited the highest concentration in urine samples, and the median concentration value for this metabolite after creatinine correction was $84.24 \mathrm{mg} / \mathrm{L}$. By 
contrast, $\mathrm{MB}_{Z} \mathrm{P}$ exhibited on average the lowest concentration in urine samples, and the median concentration for this metabolite after creatinine correction was $0.08 \mathrm{mg} / \mathrm{L}$.

Table 2. Distribution of urinary phthalate metabolite concentrations [unadjusted( $\mu \mathrm{g} / \mathrm{L}$ ) and creatinine-adjusted ( $\mu \mathrm{g} / \mathrm{g}$ creatinine)] among pregnant women $(\mathrm{N}=1003)$.

\begin{tabular}{|c|c|c|c|c|c|c|c|}
\hline \multicolumn{8}{|c|}{ Selected percentiles } \\
\hline phthalate metabolites & & DR (\%) & GM & 25th & 50th & 75th & 95th \\
\hline \multirow[t]{2}{*}{ MMP } & $\mathrm{UA}^{\mathrm{a}}$ & 76 & 0.86 & 0.15 & 1.63 & 4.47 & 17.71 \\
\hline & $C A^{b}$ & & 1.13 & 0.17 & 1.79 & 6.28 & 36.38 \\
\hline \multirow[t]{2}{*}{ MEP } & $U A^{a}$ & 97.8 & 8.49 & 4.01 & 8.64 & 20.78 & 82.26 \\
\hline & $C A^{b}$ & & 11.09 & 4.17 & 11.85 & 30.22 & 148.24 \\
\hline \multirow[t]{2}{*}{ MiBP } & $U A^{a}$ & 99.6 & 24.07 & 12.57 & 24.61 & 47.28 & 140.93 \\
\hline & $C A^{b}$ & & 31.44 & 14.77 & 32.34 & 71.07 & 240.08 \\
\hline \multirow[t]{2}{*}{ MBP } & $U A^{a}$ & 100 & 64.64 & 30.45 & 62.45 & 130.80 & 427.30 \\
\hline & $C A^{b}$ & & 84.42 & 34.64 & 84.24 & 202.32 & 698.81 \\
\hline \multirow[t]{2}{*}{ MOP } & $U A^{a}$ & 87.1 & 0.14 & 0.04 & 0.13 & 0.28 & 0.93 \\
\hline & $C A^{b}$ & & 0.18 & 0.08 & 0.17 & 0.40 & 1.38 \\
\hline \multirow[t]{2}{*}{$\mathrm{MB}_{\mathrm{Z}} \mathrm{P}$} & $U A^{a}$ & 77.5 & 0.08 & 0.03 & 0.04 & 0.16 & 0.78 \\
\hline & $C A^{b}$ & & 0.10 & 0.04 & 0.08 & 0.23 & 1.25 \\
\hline \multirow[t]{2}{*}{ MEHP } & $U^{a}$ & 93.7 & 7.18 & 2.46 & 6.78 & 37.84 & 244.35 \\
\hline & $C A^{b}$ & & 9.38 & 2.95 & 9.60 & 50.25 & 276.0 \\
\hline \multirow[t]{2}{*}{ MEOHP } & $\mathrm{UA}^{\mathrm{a}}$ & 87.4 & 5.47 & 2.24 & 6.31 & 11.92 & 44.58 \\
\hline & $C A^{b}$ & & 7.14 & 2.57 & 7.24 & 18.99 & 78.60 \\
\hline \multirow[t]{2}{*}{ MEHHP } & $U A^{a}$ & 93.7 & 4.96 & 3.51 & 7.63 & 14.63 & 40.67 \\
\hline & $C A^{b}$ & & 6.48 & 3.72 & 9.14 & 20.09 & 72.28 \\
\hline \multirow[t]{2}{*}{$\Sigma$ LMW } & $U^{a}$ & & 379.76 & 177.81 & 355.32 & 758.45 & 2449.65 \\
\hline & $C A^{b}$ & & 495.99 & 208.27 & 497.86 & 1182.32 & 4199.32 \\
\hline \multirow[t]{2}{*}{$\Sigma \mathrm{DEHP}$} & $U A^{a}$ & & 115.01 & 47.65 & 106.16 & 272.97 & 1040.99 \\
\hline & $C A^{b}$ & & 150.22 & 58.07 & 140.40 & 359.23 & 1622.26 \\
\hline
\end{tabular}

Abbreviations: UA, unadjusted; CA, creatinine-adjusted; DR, detectable rate; GM, geometric mean; MMP, mono-methy phthalate; MEP, mono-ethyl phthalate; MiBP, mono-isobutyl phthalate MBP, mono-butyl phthalate; MOP, mono-octyl phthalate; MBZ $\mathrm{P}$, mono-benzyl phthalate; MEOHP, mono-(2ethyl-5-oxohexyl) phthalate; MEHHP, mono-(2-ethyl-5-hydroxyhexyl) phthalate; MEHP, mono-(2-ethyl-5-carboxypentyl) phthalate; $\Sigma$ LMW, the molar sum of three metabolites (MMP, MEP, and MBP); $\Sigma$ DEHP, the molar sum of three metabolites (MEHP, MEHHP, and MEOHP); a The unit was $\mu \mathrm{g} / \mathrm{L} ; \mathrm{b}$ The unit was $\mu \mathrm{g} / \mathrm{g}$ creatinine.

\section{Socio-demographic variable and sampling season analyses}

In Tables 3 and 4 are listed data reflecting the effects that different demographic variables and sampling seasons have on the concentrations of LMW metabolites and high-molecular-weight (HMW) metabolites in participants' urine. Data reflecting the correlation between sampling season 
and phthalate metabolite concentration, is reported in Figures 1. The correlations between other demographic variables (maternal age, BMI, annual household income, education, passive smoking, drinking bottled water, and parity) and phthalate metabolite concentrations are reflected by data reported in Figures S1-7. The results of multivariable linear regression analyses indicated that the exposure level to phthalate metabolites during pregnancy was mainly related to maternal age, BMI, annual household income, passive smoking during pregnancy, parity, and sampling season. Notably, the concentration of MEHHP in the urine samples from pregnant women aged $\geq 30$ years was the highest. MEP, MEHP, $\Sigma$ LMW, and $\Sigma$ DEHP were the most abundant metabolites present in the urine samples collected from study participants in the overweight $\mathrm{BMI}$ group. Compared with their high-annual-income counterparts, low-annual-income participants exhibited substantially lower concentrations of MiBP, MBP, MOP, MBZ P, MEHP, and $\Sigma D E H P$, whereas middle-annual-income participants had lower concentrations of MiBP, MB ${ }_{Z} P$, MEHP, and ¿DEHP. The concentration of MEHP in urine samples from participants in the passive smoking group was higher than that in the no passive smoking group. Multiparous participants exhibited higher concentrations of MEHP and lower concentrations of MEHHP than nulliparous participants. Phthalate metabolite concentration was observed to be related to the sampling season. LMW metabolites (i.e., MMP, MEP, MiBP, MBP, and $\Sigma L M W$ ) exhibited the highest concentrations in urine samples collected in participants enrolled during the summer period. By contrast, MEHHP concentration in urine samples was lowest for participants enrolled during the summer, and MOP concentration in urine samples was lowest for participants enrolled during the spring. In this study, no statistically significant correlation was observed between phthalate metabolite exposure level and maternal education or drinking bottled water during pregnancy.

Table 3. Associations between LMW metabolite concentrations and demographic/season categories by multivariable linear regression (Intransformed, $\mu \mathrm{g} / \mathrm{g}$ creatinine) $(\mathrm{N}=1003)$. 


\begin{tabular}{|c|c|c|c|c|c|c|}
\hline \multirow[t]{2}{*}{ Variables } & & \multicolumn{5}{|c|}{$\beta$ estimates and $95 \%$ confidence intervals } \\
\hline & & MMP & MEP & MiBP & MBP & $\Sigma \mathrm{LMW}$ \\
\hline \multicolumn{7}{|l|}{ Maternal age } \\
\hline$\varangle 25$ & 342 & $-0.01(-0.36,0.35)$ & $-0.05(-0.29,0.20)$ & $0.10(-0.09,0.30)$ & $0.04(-0.14,0.22)$ & $0.03(-0.15,0.21)$ \\
\hline $25-29$ & 405 & Ref & & & & \\
\hline$\geq 30$ & 256 & $0.12(-0.25,0.50)$ & $0.17(-0.08,0.43)$ & $0.14(-0.06,0.35)$ & $0.07(-0.12,0.26)$ & $0.11(-0.07,0.30)$ \\
\hline \multicolumn{7}{|l|}{ BMI $\left(\mathrm{kg} / \mathrm{m}^{2}\right)$} \\
\hline$\bigotimes 18.4$ & 105 & $0.23(-0.26,0.72)$ & $0.01(-0.33,0.35)$ & $-0.12(-0.39,0.15)$ & $-0.07(-0.32,0.17)$ & $-0.04(-0.29,0.20)$ \\
\hline $18.5-23.9$ & 615 & Ref & & & & \\
\hline$\geq 24$ & 283 & $0.01(-0.33,0.34)$ & $0.45(0.23,0.68)$ & $0.16(-0.03,0.34)$ & $0.15(-0.02,0.32)$ & $0.19(0.02,0.36)$ \\
\hline \multicolumn{7}{|l|}{ Household income } \\
\hline$\bigotimes 100000$ & 174 & $0.01(-0.38,0.59)$ & $0.02(-0.31,0.36)$ & $-0.63(-0.89,-0.36)$ & $-0.30(-0.54,-0.05)$ & $-0.22(-0.46,0.03)$ \\
\hline $100000-150000$ & 582 & $-0.14(-0.51,0.23)$ & $-0.04(-0.30,0.21)$ & $-0.25(-0.45,-0.05)$ & $-0.12(-0.31,0.07)$ & $-0.10(-0.28,0.08)$ \\
\hline$\geq 150000$ & 231 & Ref & & & & \\
\hline Don't know & 16 & $0.06(-0.14,2.31)$ & $-0.02(-1.03,0.64)$ & $-0.19(-0.86,0.47)$ & $0.09(-0.52,0.71)$ & $0.07(-0.53,0.68)$ \\
\hline \multicolumn{7}{|l|}{ Education } \\
\hline middle school or below & 596 & $0.22(-0.28,0.71)$ & $0.03(-0.28,0.34)$ & $0.07(-0.17,0.32)$ & $0.10(-0.13,0.32)$ & $0.11(-0.12,0.33)$ \\
\hline $\begin{array}{l}\text { High school and middle special } \\
\text { school }\end{array}$ & 266 & $0.22(-0.38,0.59)$ & $0.21(-0.12,0.55)$ & $0.04(-0.23,0.31)$ & $0.11(-0.14,0.36)$ & $0.12(-0.12,0.36)$ \\
\hline College degree or above & 141 & Ref & & & & \\
\hline \multicolumn{7}{|l|}{ Passive smoking } \\
\hline Yes & 117 & $0.07(-0.40,0.54)$ & $0.00(-0.32,0.32)$ & $-0.01(-0.27,0.25)$ & $0.08(-0.16,0.31)$ & $0.08(-0.15,0.31)$ \\
\hline NO & 886 & Ref & & & & \\
\hline \multicolumn{7}{|l|}{ Drinking bottled water } \\
\hline Yes & 927 & $-0.19(-0.75,0.38)$ & $0.16(-0.23,0.54)$ & $-0.17(-0.48,0.13)$ & $-0.06(-0.34,0.23)$ & $-0.05(-0.33,0.23)$ \\
\hline NO & 76 & Ref & & & & \\
\hline \multicolumn{7}{|l|}{ Parity } \\
\hline Nulliparous & 397 & Ref & & & & \\
\hline Multiparous & 606 & $0.02(-0.32,0.35)$ & $-0.06(-0.29,0.16)$ & $0.04(-0.14,0.22)$ & $0.03(-0.13,0.20)$ & $0.01(-0.16,0.17)$ \\
\hline \multicolumn{7}{|l|}{ Sampling season } \\
\hline Spring & 255 & $-0.07(-0.43,0.30)$ & $0.50(0.25,0.75)$ & $0.14(0.22,0.62)$ & $0.77(0.58,0.95)$ & $0.76(0.58,0.94)$ \\
\hline Summer & 75 & $0.95(0.37,1.53)$ & $1.37(0.98,1.77)$ & $0.18(0.60,1.23)$ & $1.74(1.45,2.03)$ & $1.78(1.50,2.07)$ \\
\hline Fall & 232 & $0.93(0.54,1.32)$ & $0.70(0.44,0.97)$ & $0.17(0.32,0.74)$ & $0.66(0.46,0.85)$ & $0.67(0.48,0.87)$ \\
\hline Winter & 441 & Ref & & & & \\
\hline
\end{tabular}

LMW metabolite including MMP, MEP MiBP, MBP and $\Sigma$ LMW. Bold font indicates $\mathrm{p}$ value $\mathbb{0} 0.05$.

Table 4. Associations between HMW metabolite concentrations and demographic/season categories by multivariable linear regression (Intransformed, $\mu \mathrm{g} / \mathrm{g}$ creatinine) $(\mathrm{N}=1003)$. 


\begin{tabular}{|c|c|c|c|c|c|c|c|}
\hline \multirow[t]{2}{*}{ Variables } & \multirow[b]{2}{*}{$\mathbf{N}$} & \multicolumn{6}{|c|}{$\beta$ estimates and $95 \%$ confidence intervals } \\
\hline & & MOP & $\mathrm{MB}_{\mathrm{Z}} \mathrm{P}$ & MEHP & MEOHP & MEHHP & $\Sigma D E H P$ \\
\hline \multicolumn{8}{|l|}{$\begin{array}{l}\text { Maternal } \\
\text { age }\end{array}$} \\
\hline$\varangle 25$ & 342 & $-0.05(-0.23,0.13)$ & $-0.04(-0.24,0.16)$ & $-0.25(-0.60,0.09)$ & $0.15(-0.07,0.37)$ & $0.24(-0.06,0.55)$ & $-0.03(-0.23,0.17)$ \\
\hline $25-29$ & 405 & Ref & & & & & \\
\hline$\geq 30$ & 256 & $0.15(-0.04,0.34)$ & $-0.01(-0.22,0.20)$ & $0.14(-0.22,0.51)$ & $0.01(-0.22,0.25)$ & $0.40(0.08,0.72)$ & $0.15(-0.07,0.36)$ \\
\hline \multicolumn{8}{|l|}{$\begin{array}{l}\text { BMl } \\
\left(\mathrm{kg} / \mathrm{m}^{2}\right)\end{array}$} \\
\hline$\otimes 18.5$ & 105 & $-0.15(-0.40,0.10)$ & $-0.22(-0.49,0.06)$ & $0.19(-0.29,0.66)$ & $-0.18(-0.49,0.13)$ & $-0.24(-0.66,0.18)$ & $-0.05(-0.33,0.23)$ \\
\hline $18.5-23.9$ & 615 & Ref & & & & & \\
\hline$\geq 24$ & 283 & $0.07(-0.10,0.24)$ & $-0.02(-0.21,0.16)$ & $0.67(0.34,0.99)$ & $-0.01(-0.22,0.20)$ & $0.21(-0.08,0.49)$ & $0.26(0.07,0.45)$ \\
\hline \multicolumn{8}{|l|}{$\begin{array}{l}\text { Household } \\
\text { income }\end{array}$} \\
\hline$\otimes 100000$ & 174 & $-0.42(-0.67,-0.18)$ & $-0.49(-0.76,-0.22)$ & $-0.49(-0.96,-0.02)$ & $-0.17(-0.47,0.14)$ & $-0.23(-0.65,0.19)$ & $-0.41(-0.68,-0.13)$ \\
\hline $\begin{array}{l}100000- \\
150000\end{array}$ & 582 & $-0.21(-0.40,-0.02)$ & $-0.21(-0.42,-0.01)$ & $-0.48(-0.84,-0.12)$ & $-0.17(-0.40,0.06)$ & $-0.22(-0.54,0.10)$ & $-0.30(-0.51,-0.09)$ \\
\hline$\geq 150000$ & 231 & Ref & & & & & \\
\hline Don't know & 16 & $0.11(-0.51,0.73)$ & $0.29(-0.39,0.97)$ & $-0.42(-1.61,0.77)$ & $0.43(-0.33,1.20)$ & $0.49(-0.55,1.53)$ & $-0.07(-0.77,0.62)$ \\
\hline \multicolumn{8}{|l|}{ Education } \\
\hline $\begin{array}{l}\text { middle } \\
\text { school or } \\
\text { below }\end{array}$ & 596 & $-0.02(-0.25,0.20)$ & $-0.13(-0.38,0.12)$ & $-0.10(-0.54,0.33)$ & $-0.22(-0.50,0.06)$ & $0.19(-0.20,0.57)$ & $-0.11(-0.36,0.15)$ \\
\hline $\begin{array}{l}\text { High school } \\
\text { and middle } \\
\text { special } \\
\text { school }\end{array}$ & 266 & $0.19(-0.06,0.44)$ & $-0.20(-0.47,0.08)$ & $-0.04(-0.51,0.44)$ & $-0.21(-0.51,0.10)$ & $0.17(-0.25,0.59)$ & $-0.08(-0.36,0.20)$ \\
\hline $\begin{array}{l}\text { College } \\
\text { degree or } \\
\text { above }\end{array}$ & 141 & Ref & & & & & \\
\hline \multicolumn{8}{|l|}{$\begin{array}{l}\text { Passive } \\
\text { smoking }\end{array}$} \\
\hline Yes & 117 & $-0.04(-0.28,0.20)$ & $-0.09(-0.35,0.18)$ & $0.49(0.03,0.95)$ & $-0.25(-0.55,0.04)$ & $-0.03(-0.43,0.37)$ & $0.09(-0.18,0.36)$ \\
\hline NO & 886 & Ref & & & & & \\
\hline \multicolumn{8}{|l|}{$\begin{array}{l}\text { Drinking } \\
\text { bottled } \\
\text { water }\end{array}$} \\
\hline Yes & 927 & $0.17(-0.12,0.45)$ & $-0.05(-0.37,0.26)$ & $-0.04(-0.59,0.51)$ & $0.01(-0.34,0.36)$ & $-0.17(-0.65,0.31)$ & $-0.10(-0.42,0.22)$ \\
\hline NO & 76 & Ref & & & & & \\
\hline \multicolumn{8}{|l|}{ Parity } \\
\hline Nulliparous & 397 & Ref & & & & & \\
\hline Multiparous & 606 & $0.03(-0.14,0.20)$ & $0.05(-0.14,0.23)$ & $0.37(0.05,0.69)$ & $0.13(-0.08,0.34)$ & $-0.46(-0.75,-0.18)$ & $0.17(-0.02,0.36)$ \\
\hline \multicolumn{8}{|l|}{$\begin{array}{l}\text { Sampling } \\
\text { season }\end{array}$} \\
\hline Spring & 255 & $-0.30(-0.48,-0.11)$ & $-0.87(-1.08,-0.67)$ & $0.14(-0.21,0.50)$ & $-0.05(-0.28,0.18)$ & $0.60(0.28,0.91)$ & $0.06(-0.15,0.27)$ \\
\hline Summer & 75 & $-0.28(-0.57,0.01)$ & $-0.69(-1.01,-0.36)$ & $-0.37(-0.93,0.20)$ & $0.33(-0.04,0.69)$ & $-0.73(-1.22,-0.23)$ & $0.10(-0.23,0.43)$ \\
\hline Fall & 232 & $0.00(-0.20,0.20)$ & $-0.46(-0.68,-0.25)$ & $0.24(-0.14,0.62)$ & $-0.37(-0.62,-0.13)$ & $0.41(0.08,0.75)$ & $0.10(-0.12,0.32)$ \\
\hline Winter & 441 & Ref & & & & & \\
\hline
\end{tabular}

Page 10/17 
HMW metabolite including MOP, MB $\mathrm{Z}$ P, MEHP, MEOHP, MEHHP and $\Sigma$ DEHP. Bold font indicates $p$ value $<0.05$.

\section{Correlations between phthalate metabolite concentrations}

In order to assess the variations in the potential sources of phthalate metabolite exposure, the correlations between urinary concentrations of individual phthalate metabolites in 1003 pregnant women were identified by Spearman's rank correlation coefficient analysis. A significant correlation among phthalate metabolites was recognized; specifically, there was a strong correlation between the concentrations of the four LMW phthalates, MMP, MEP, MiBP, and MBP, (the relevant Spearman's coefficients ranged between 0.534 and 0.855 ). On the contrary, the correlation between the three DEHP, MEHP, MEOHP, and MEHHP, was observed to be weak (the relevant Spearman's coefficients ranged between 0.228 and 0.444). The results of the mentioned analyses are listed in Table S3.

\section{Comparison of uncorrected median concentrations of phthalate metabolites in different studies}

As can be evinced from the data reported in Figure S8, a comparison was made between the results obtained herein and those obtained in several international studies; in the present study, the exposure levels of $M B P$ were observed to be the highest, while those of $\mathrm{MB}_{Z} \mathrm{P}$ were the lowest; the MEP exposure level measured here in is similar to that reported in other studies conducted in Japan and Korea (Suzuki et al., 2010; Lee et al., 2020), but it is lower than that reported in studies conducted in Denmark, Spain, United States, and Canada (Tefre et al., 2014; Casas et al., 2011; Cantonwine et al., 2014; Arbuckle et al., 2014); the MiBP exposure level measured in this study is higher than that reported in Taiwan, China, Korea, and Thailand (Lin et al., 2010; Lee et al., 2020) and lower than that measured in Denmark and Spain (Tefre et al., 2014; Casas et al., 2011); the MEHP exposure level determined herein agrees with that reported in other studies conducted in Japan and Korea (Suzuki et al., 2010; Lee et al., 2020), but it is higher than that reported in studies conducted in Denmark, Spain, United States and Canada (Tefre et al., 2014; Casas et al., 2011; Cantonwine et al., 2014; Arbuckle et al., 2014); the exposure levels measured in the present study for MEOHP and MEHHP are lower than those reported in studies conducted in Taiwan, China, Spain, United States and Canada (Lin et al., 2010; Casas et al., 2011; Cantonwine et al., 2014; Arbuckle et al., 2014), but they are consistent with those reported in studies conducted in Japan and Korea (Suzuki et al., 2010; Lee et al., 2020).

\section{Discussion}

In this study, the concentrations of nine phthalate metabolites were measured in the urine samples of 1003 Chinese pregnant women during their third trimester of pregnancy. Notably, the detectable rates of the various analytes were observed to range between $76 \%$ and $100 \%$; in particular, the detectable rates of MBP, MEP, MiBP, MEHHP, and MEHP were all > 90\%, which are values similar to those reported in studies

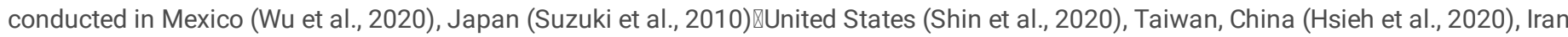
(Darvishmotevalli et al., 2019) and Israel (Berman et al., 2009); by contrast, the detectable rates measured herein for MMP, MB $\mathrm{Z}_{\mathrm{Z}}$, and $\mathrm{MEOHP}$ are significantly lower than those reported in the studies just mentioned. Remarkably, the detectable rate of MOP was observed to vary greatly between studies: the lowest reported values are $0.5 \%$, from a study conducted in Denmark (Tefre et al., 2014), and 63\%, from a study conducted in Poland (Polańska et al., 2016), which are significantly lower values than that measured herein, $87.1 \%$. The difference in detectable rates between studies conducted in different geographic areas may be related to differences in eating and living habits of the study populations as well as differences in the industrialization and economic levels between geographic areas.

The median concentrations of the nine phthalate metabolites measured in urine samples collected from the participants of our study are as follows $₫$ MBP, $62.45 \mathrm{mg} / \mathrm{L} ; \mathrm{MiBP}, 24.61 \mathrm{mg} / \mathrm{L} ; \mathrm{MEP}, 8.64 \mathrm{mg} / \mathrm{L} ; \mathrm{MEHHP}, 7.63 \mathrm{mg} / \mathrm{L} ; \mathrm{MEHP}, 6.78 \mathrm{mg} / \mathrm{L} ; \mathrm{MEOHP,} 6.31 \mathrm{mg} / \mathrm{L} ; \mathrm{MMP}, 1.63 \mathrm{mg} / \mathrm{L} ; \mathrm{MOP}$, $0.13 \mathrm{mg} / \mathrm{L}$; and $\mathrm{MB}_{Z} \mathrm{P}, 0.04 \mathrm{mg} / \mathrm{L}$. Our above results are compared with published international studies conducted in Japan (Suzuki et al., 2010), Taiwan, China (Lin et al., 2010), Korea and Thailand (Lee et al., 2020), Denmark (Tefre et al., 2014), Spain (Casas et al., 2011), United States (Cantonwine et al., 2014), and Canada (Arbuckle et al., 2014). Remarkably, the herein-measured median concentration of MEP is similar to that reported for the rest of the Asian region, but it is significantly lower than that reported in studies conducted in the European and American regions. In particular, MEP concentrations up to $324 \mathrm{mg} / \mathrm{L}$ have been measured in Spain (Casas et al., 2011) and up to $99.2 \mathrm{mg} / \mathrm{L}$ in United States (Cantonwine et al., 2014), which are 11 to 36 times as large as the median concentration measured for the said metabolite in our survey. These striking differences may be related to the more extensive use that women in European and American countries make of personal care products (PCPs), such as perfumes, nail polish, and cosmetics (Parlett et al., 2013). Indeed, these products contain as a component diethyl phthalate (DEP), which is the parent compound of MEP. Although China is one of the three largest consumer countries of PCPs in the world (Wang et al., 2018), people living in China's rural areas have less access to PCPs than people living in urban areas, resulting in low MEP levels detected in people living in the rural areas of China (Cheng et al., 2021); in fact, almost all participants of our study were from rural China. Similar to the results of a previously published study on a Chinese pregnant women cohort, median concentrations of total MBP were the highest (Gao et al., 2017; Zhu et al., 2016), and the concentration of MBP is two to six times higher than that measured in studies conducted in South Korea, Thailand (Lee et al., 2020), and European and American countries (Tefre et al., 2014; Casas et al., 2011; Cantonwine et al., 2014; Arbuckle et al., 2014); this difference may be related to the pollution caused by China's heavy use of DBP in industrial production (Guo et al., 2011). The median 
concentration of $\mathrm{MB}_{Z} \mathrm{P}$ determined in our survey is clearly significantly lower than the level of this phthalate metabolite measured in all other countries and regions (Suzuki et al., 2010; Lin et al., 2010; Lee et al., 2020; Tefre et al., 2014; Casas et al., 2011; Cantonwine et al., 2014; Arbuckle et al., 2014). Similarly, the results of previous investigations (He et al., 2019; Guo et al., 2020) also suggested that the exposure to MB $\mathrm{P}_{\mathrm{Z}}$ in South China is extremely low. Limited evidence exists that $\mathrm{MB}_{Z} \mathrm{P}$ exposure in China is mainly associated with exposure to cereal, seafood, and cooking oil, so exposure to $\mathrm{MB}_{Z} \mathrm{P}$ differs between countries and foods (Wang et al., 2018). Therefore, the low level of $\mathrm{MB}_{Z} \mathrm{P}$ exposure measured herein may be related to the dietary structure and dietary sources of the participants of our study.

We found that participants with BMI $\geq 24 \mathrm{~kg} / \mathrm{m}^{2}$ had higher levels of MEP, MEHP, $\sum$ LMW and $\Sigma D E H P$ in urine samples; the existence of this phenomenon is also supported by previous research data (Yaghjyan et al., 2015; Hatch et al., 2008). The compelling reason for this trend may be that phthalates exhibit a degree of lipophilicity, so they can be stored in the adipose tissue; therefore, people with higher BMI may exhibit higher concentrations of urinary phthalate metabolites (Philips et al., 2017). In addition, foods are an important source of phthalate metabolites exposure (Dualde et al., 2020), indeed, study participants with high BMI values tend to have higher food intake than those with low BMI values, which may account for the observed difference in exposure to phthalate metabolites. Compared with their high-annual-income peers, lower-annual-income participants exhibit lower urine levels of MiBP, MBP, MOP, MB $\mathrm{P}, \mathrm{MEHP}$, and $\Sigma \mathrm{DEHP}$, a result that is inconsistent with those reported in previously published studies (Wenzel et al., 2018; Wang et al., 2018). The reasons for this inconsistency may have to do with the different income levels among different countries. In addition, people with lower incomes may be less exposed to cosmetics and food packaging products, which may also contribute to the mentioned observation.

The results of previously published studies indicated that the distribution of some phthalate metabolites in the environment exhibits seasonal characteristics (Chen et al., 2018; Zhang et al., 2019). Indeed, higher levels of the LMW phthalate metabolites (i.e., MMP, MEP, MiBP, MBP, and $\Sigma$ LMW) were measured in of our study in participants recruited during the summer. Similar results were obtained for pregnant women, young children and general population in China (Guo et al., 2020; Liao et al., 2018; Yang et al., 2021). The reasons for the observed seasonal effects on metabolite concentrations remain unclear. Research results indicate that LMW phthalate metabolites, such as DEP and DBP, are mainly used in cosmetics and PCPs, and use of these products will lead to high exposure to phthalate metabolites (Hsieh et al., 2019; Koniecki et al., 2011). During the summer, women may use PCPs like perfumes, shampoos, nail polish, and sunscreen more frequently than in other seasons, and phthalate metabolites absorbed by skin is more frequent, resulting in higher exposure to LMW phthalate metabolites during the summer. Moreover, Gao et al. discovered that Chinese pregnant women stayed longer indoor daily in summer than in winter (Gao et al., 2017), cosmetics and PCPs have been suggested to be important sources of phthalates in indoor dusts in China (Zhang et al., 2013), and the higher temperature would cause an increase in the release of these phthalates due to their volatility (Chen et al., 2018; Zhang et al., 2019), resulting in the human body being exposed to increased amounts of LMW phthalate metabolites indoors. However, different phthalates are affected differently by the temperature (Kashyap et al., 2018). These differences may in part explain the different exposure levels of different metabolites in different seasons, although there may be other reasons for them that we don't yet understand. Further research in this field is thus necessary.

Our research has some limitations. First, a single urine sample was collected from each study participant for testing, so the measured phthalate metabolite content does not represent the average level during late pregnancy. Second, humans are exposed to phthalates from a variety of sources and pathways, and we only analyzed demographic variables and sampling season; by this approach, we may be missing other potentially important predictive variables, such as dietary and PCPs use habits. Considering, however, that our sample size is relatively large and the phthalate metabolites are examined according to the same standard, using the same instrumentation, and the same testing personnel, and the quality control of the data is reliable, we have reason to believe that our test data closely reflect the "real" situation of the study population.

\section{Conclusion}

To the best of our knowledge, this is the first study to investigate phthalate metabolite exposure characteristics among pregnant women in Southwest China. Phthalate metabolites present a demographic and seasonal differential distribution among the study population, an observation that will help inform the development of targeted interventions to reduce exposure to these potentially harmful chemicals during pregnancy.

\section{Abbreviations}

DEHP - mono(2-ethylhexyl) phthalate

DBP - di-n-butyl phthalate

BMI - body mass index

GC-MS/MS - high-performance gas chromatography mass spectrometry 
MMP - mono-methyl phthalate

MEP - mono-methyl phthalate

MiBP - mono-ethyl phthalate

MBP - mono-butyl phthalate

MOP - mono-octyl phthalate

MBzP - mono-benzyl phthalate

MEHP - mono(2-ethylhexyl) phthalate

MEOHP - mono(2-ethyl-5-oxohexyl) phthalate

MEHHP - mono(2-ethyl-5-hydroxyhexyl) phthalate

LOD - the limit of detection

LMW - low-molecular-weight

$\Sigma \mathrm{LMW}$ - the total sum of low-molecular-weight phthalates (MMP, MEP and MBP)

¿DEHP - the total sum of the three metabolites (MEHP, MEOHP and MEHHP)

SD - standard deviation

UA - unadjusted

CA - creatinine-adjusted

DR - detectable rate

GM - geometric mean

HMW - high-molecular-weight

$\mathrm{Cl}$ - confidence interval

PCPs - personal care products

DEP - diethyl phthalat

\section{Declarations}

\section{Acknowledgments}

The authors thank all the participants and investigators

\section{Ethical Approval}

This study was ethically reviewed by the Affiliated Hospital of Zunyi Medical University (batch No.: KLL-2019-006).

\section{Consent to Participate}

All participates agreed to participate in this study and signed the informed consents.

\section{Consent to Publish}

The authors declare that this manuscript does not contain any individual person's data and material in any form.

\section{Competing interests}

The authors declare no competing interests. 
This work was supported by National Key R\&D Program of China (2018YFC1004300, 2018YFC1004302) and Science \& Technology Program of Guizhou Province, China (QKHHBZ [2020]3002).

\section{Availability of data and materials}

Data associated with the present study can be accessed on request to the author (630140512@qq.com).

\section{Author Contributions}

Juan Liao: Formal analysis, Investigation, Validation, Data curation, Writing-original draft. Derong Fang: Investigation, Data curation. Yijun Liu: Data curation, Validation. Shimin Xiong: Data curation, Validation. Xia Wang: Methodology, Validation. Yingkuan Tian: Methodology, Validation. Haonan Zhang: Methodology, Validation. Songlin An: Investigation, Conceptualization. Caidie He: Investigation, Conceptualization. Wei Chen: Investigation, Conceptualization. Xiang Liu: Investigation, Conceptualization. Nian Wu: Data curation, Conceptualization. Kunming Tian:Investigation, Validation. Linglu Wang: Investigation, Validation. Ya Zhang: Investigation, Data curation. Hongyu Yuan: Investigation, Data curation. Li Zhang: Investigation, Data curation. Quan Li: Project administration, Investigation, Validation, Resources. Xubo Shen: Project administration, Investigation, Validation, Resources. Yuanzhong Zhou: Project administration, Investigation, Validation, Resources, Writingreview \& editing, Funding acquisition.

\section{References}

1. Arbuckle T.E., Davis K., Marro L., Fisher M., Legrand M., LeBlanc A., et al., 2014. Phthalate and bisphenol A exposure among pregnant women in Canada - Results from the MIREC study. Environ. Int. 68, 55-65. https://doi.org/10.1016/j.envint.2014.02.010.

2. Benjamin S., Masai E., Kamimura N., Takahashi K., Anderson R.C., Faisal P.A., 2017. Phthalate impact human health: Epidemiological evidences and plausible mechanism of action. J. Hazard. Mater. 340, 360-383. https://doi.org/10.1016/j.jhazmat.2017.06.036

3. Bergman Å., Heindel J.J., Kasten T., Kidd K.A., Jobling S., Neira M., et al., 2013. The Impact of Endocrine Disruption: A Consensus Statement on the State of the Science. Environ. Health Perspect. 121, A104-6. https://doi.org/10.1289/ehp.1205448.

4. Berman T., Hochner-Celnikier D., Calafat A.M., Needham L.L., Amitai Y., Wormser U., et al., 2009. Phthalate exposure among pregnant women in Jerusalem, Israel: Results of a pilot study. Environ. Int. 35, 353-357. https://doi.org/10.1016/j.envint.2008.08.010.

5. Broe A., Pottegård A., Hallas J., Ahern T.P., Lamont R.F., Damkier P., 2019. Phthalate exposure from drugs during pregnancy and possible risk of preterm birth and small for gestational age. EUR J. OBSTET GYN R. B. 240, 293-299. https://doi.org/10.1016/j.ejogrb.2019.07.023.

6. Calafat A.M., Valentin-Blasini L., Ye X., 2015. Trends in Exposure to Chemicals in Personal Care and Consumer Products. Curr. Environ Health Rep 2, 348-355. https://doi.org/10.1007/s40572-015-0065-9.

7. Cantonwine D.E., Cordero J.F., Rivera-González L.O., Anzalota Del Toro L.V., Ferguson K.K., Mukherjee B., et al., 2014. Urinary phthalate metabolite concentrations among pregnant women in Northern Puerto Rico: Distribution, temporal variability, and predictors. Environ. Int. 62 1-11. https://doi.org/10.1016/j.envint.2013.09.014.

8. Casas L., Fernández M.F., Llop S., Guxens M., Ballester F., Olea N., et al., 2011. Urinary concentrations of phthalates and phenols in a population of Spanish pregnant women and children. Environ. Int. 37, 858-866. https://doi.org/10.1016/j.envint.2011.02.012.

9. Chen M., Zhao S., Guo W., Zhu Y., Pan L., Xie Z., et al., 2020. Maternal exposure to Di-n-butyl phthalate (DBP) aggravate gestational diabetes mellitus via FoxM1 suppression by pSTAT1 signalling. Ecotoxicol. Environ. Saf. 205, 111154. https://doi.org/10.1016/j.ecoenv.2020.111154.

10. Chen Y., Lv D., Li X., Zhu T., 2018. PM2.5-bound phthalates in indoor and outdoor air in Beijing: Seasonal distributions and human exposure via inhalation. Environ. Pollut. 241, 369-377. https://doi.org/10.1016/j.envpol.2018.05.081.

11. Cheng B., Xu P., Wei R., Li X., Sheng J., Wang S., et al., 2021. Levels and determinants of urinary phthalate metabolites in Chinese communitydwelling older adults. Sci. Total Environ. 762, 144173. https://doi.org/10.1016/j.scitotenv.2020.144173.

12. Darvishmotevalli M., Bina B., Feizi A., Ebrahimpour K., Pourzamani H., Kelishadi R., 2019. Monitoring of urinary phthalate metabolites among pregnant women in Isfahan, Iran: the PERSIAN birth cohort. J. Environ Health Sci 17, 969-978. https://doi.org/10.1007/s40201-019-00412-8.

13. De Cock M., De Boer M.R., Lamoree M., Legler J., Van De Bor M., 2015. Prenatal exposure to endocrine disrupting chemicals and birth weight -A prospective cohort study. J. Environ. Sci. Health Part A Toxic-Hazard. Subst. Environ. Eng. 51, 178-185. https://doi.org/10.1080/10934529.2015.1087753.

14. Dualde P., Leon N., Pardo O., Coscollà C., Vento M., Pastor A., et al., 2020. Risk assessment of exposure to phthalates in breastfeeding women using human biomonitoring. Chemosphere 255, 127003. https://doi.org/10.1016/j.chemosphere.2020.127003.

15. Ferguson K.K., Rosen E.M., Rosario Z., Feric Z., Calafat A.M., McElrath T.F., et al., 2019. Environmental phthalate exposure and preterm birth in the PROTECT birth cohort. Environ. Int. 132, 105099. https://doi.org/10.1016/j.envint.2019.105099. 
16. Gao H., Wang Y., Huang K., Han Y., Zhu Y., Zhang Q., et al., 2019. Prenatal phthalate exposure in relation to gestational age and preterm birth in a prospective cohort study. Environ. Res. 176, 108530. https://doi.org/10.1016/j.envres.2019.108530.

17. Gao H., Zhang Y., Huang K., Yan S., Mao L., Ge X., et al., 2017. Urinary concentrations of phthalate metabolites in early pregnancy associated with clinical pregnancy loss in Chinese women. Sci. Rep. 7, 6800. https://doi.org/10.1038/s41598-017-06450-2.

18. Gao H., Zhu Y., Xu Y., Zhang Y., Yao H., Sheng J., et al., 2017. Season-dependent concentrations of urinary phthalate metabolites among Chinese pregnant women: Repeated measures analysis. Environ. Int. 104, 110-117. https://doi.org/10.1016/j.envint.2017.03.021.

19. Guo J., Wu M., Gao X., Chen J., Li S., Chen B., et al., 2020. Meconium Exposure to Phthalates, Sex and Thyroid Hormones, Birth Size and Pregnancy Outcomes in 251 Mother-Infant Pairs from Shanghai. Int. J. Environ. Res. Public Health $17,7711$. https://doi.org/10.3390/ijerph17217711.

20. Guo Y., Wu Q., Kannan K., 2011. Phthalate metabolites in urine from China, and implications for human exposures. Environ. Int. $37,893-898$. https://doi.org/10.1016/j.envint.2011.03.005.

21. Hatch E.E., Nelson J.W., Qureshi M.M., Weinberg J., Moore L.L., Singer M., et al., 2008. Association of urinary phthalate metabolite concentrations with body mass index and waist circumference: a cross-sectional study of NHANES data, 1999-2002. Environ. Health 7. https://doi.org/10.1186/1476-069X-7-27.

22. He X., Zang J., Liao P., Zheng Y., Lu Y., Zhu Z., et al., 2019. Distribution and Dietary Predictors of Urinary Phthalate Metabolites among Pregnant Women in Shanghai, China. Int. J. Environ. Res. Public Health 16, 1366. https://doi.org/10.3390/ijerph16081366.

23. Hsieh C., Chang Y., Hu A., Chen M., Sun C., Situmorang R.F., et al., 2019. Personal care products use and phthalate exposure levels among pregnant women. Sci. Total Environ. 648, 135-143. https://doi.org/10.1016/j.scitotenv.2018.08.149.

24. Ipapo K.N., Factor-Litvak P., Whyatt R.M., Calafat A.M., Diaz D., Perera F., et al., 2017. Maternal prenatal urinary phthalate metabolite concentrations and visual recognition memory among infants at 27 weeks. Environ. Res. 155, 7-14. https://doi.org/10.1016/j.envres.2017.01.019.

25. James-Todd T.M., Meeker J.D., Huang T., Hauser R., Ferguson K.K., Rich-Edwards J.W., et al., 2016. Pregnancy urinary phthalate metabolite concentrations and gestational diabetes risk factors. Environ. Int. 96, 118-126. https://doi.org/10.1016/j.envint.2016.09.009.

26. Kashyap D., Agarwal T., 2018. Concentration and factors affecting the distribution of phthalates in the air and dust: A global scenario. Sci. Total Environ. 635, 817-827. https://doi.org/10.1016/j.scitotenv.2018.04.158.

27. Koniecki D., Wang R., Moody R.P., Zhu J., 2011. Phthalates in cosmetic and personal care products: Concentrations and possible dermal exposure. Environ. Res. 111, 329-336. https://doi.org/10.1016/j.envres.2011.01.013.

28. Lee G., Kim S., Kho Y., Kim S., Lee S., Choi G., et al., 2020. Urinary levels of phthalates and DINCH metabolites in Korean and Thai pregnant women across three trimesters. Sci. Total Environ. 711, 134822. https://doi.org/10.1016/j.scitotenv.2019.134822.

29. Liao C., Liu W., Zhang J., Shi W., Wang X., Cai J., et al., 2018. Associations of urinary phthalate metabolites with residential characteristics, lifestyles, and dietary habits among young children in Shanghai, China. Sci. Total Environ. 616-617, 1288-1297. https://doi.org/10.1016/j.scitotenv.2017.10.189.

30. Liao K., Kuo P., Huang H., Chang J., Chiang H., Huang P., 2018. Increased risk of phthalates exposure for recurrent pregnancy loss in reproductive-aged women. Environ. Pollut. 241, 969-977. https://doi.org/10.1016/j.envpol.2018.06.022.

31. Lin S., Ku H., Su P., Chen J., Huang P., Angerer J., et al., 2011. Phthalate exposure in pregnant women and their children in central Taiwan. Chemosphere 82, 947-955. https://doi.org/10.1016/j.chemosphere.2010.10.073.

32. Messerlian C., Wylie B.J., Mínguez-Alarcón L., Williams P.L., Ford J.B., Souter I.C., et al., 2016. Urinary Concentrations of Phthalate Metabolites and Pregnancy Loss Among Women Conceiving with Medically Assisted Reproduction. Epidemiology 27, $879-888$. https://doi.org/10.1097/EDE.0000000000000525.

33. Mu D., Gao F., Fan Z., Shen H., Peng H., Hu J., 2015. Levels of Phthalate Metabolites in Urine of Pregnant Women and Risk of Clinical Pregnancy Loss. Environ. Sci. Technol. 49, 10651-10657. https://doi.org/10.1021/acs.est.5b02617.

34. Parlett L.E., Calafat A.M., Swan S.H., 2013. Women's exposure to phthalates in relation to use of personal care products. J. Exposure Sci. Environ. Epidemiol. 23, 197-206. https://doi.org/10.1038/jes.2012.105.

35. Philips E.M., Jaddoe V.W.V., Trasande L., 2017. Effects of early exposure to phthalates and bisphenols on cardiometabolic outcomes in pregnancy and childhood. Reprod. Toxicol. 68, 105-118. https://doi.org/10.1016/j.reprotox.2016.08.015.

36. Polańska K., Ligocka D., Sobala W., Hanke W., 2016. Effect of environmental phthalate exposure on pregnancy duration and birth outcomes. Int. J. Occup. Med. Environ. Health 29, 683-697. https://doi.org/10.13075/ijomeh.1896.00691.

37. Polinski K.J., Dabelea D., Hamman R.F., Adgate J.L., Calafat A.M., Ye X., et al., 2018. Distribution and predictors of urinary concentrations of phthalate metabolites and phenols among pregnant women in the Healthy Start Study. Environ. Res. 162, $308-317$. https://doi.org/10.1016/j.envres.2018.01.025. 
38. Shin H., Dhar U., Calafat A.M., Nguyen V., Schmidt R.J., Hertz-Picciotto I., 2020. Temporal Trends of Exposure to Phthalates and Phthalate Alternatives in California Pregnant Women during 2007-2013: Comparison with Other Populations. Environ. Sci. Technol. 54, $13157-13166$. https://doi.org/10.1021/acs.est.0c03857.

39. Suzuki Y., Niwa M., Yoshinaga J., Mizumoto Y., Serizawa S., Shiraishi H., 2010. Prenatal exposure to phthalate esters and PAHs and birth outcomes. Environ. Int. 36, 699-704. https://doi.org/10.1016/j.envint.2010.05.003.

40. Tefre De Renzy-Martin K., Frederiksen H., Christensen J.S., Boye Kyhl H., Andersson A., Husby S., et al., 2014. Current exposure of 200 pregnant Danish women to phthalates, parabens and phenols. Reproduction 147, 443-453. https://doi.org/10.1530/REP-13-0461.

41. Toft G., Jönsson B.A.G., Lindh C.H., Jensen T.K., Hjollund N.H., Vested A., et al., 2012. Association between Pregnancy Loss and Urinary Phthalate Levels around the Time of Conception. Environ. Health Perspect. 120, 458-463. https://doi.org/10.1289/ehp.1103552.

42. Wang W., Leung A.O.W., Chu L.H., Wong M.H., 2018. Phthalate contamination in China: Status, trends and human exposure-with an emphasis on oral intake. Environ. Pollut. 238, 771-782. https://doi.org/10.1016/j.envpol.2018.02.088.

43. Wang Y., Liu C., Chen Y., Chen H., Yang P., Wang P., et al., 2018. Predictors and correlations of phthalate metabolite concentrations in urine and seminal plasma among reproductive-aged men. Environ. Res. 161, 336-344. https://doi.org/10.1016/j.envres.2017.11.027.

44. Wenzel A.G., Brock J.W., Cruze L., Newman R.B., Unal E.R., Wolf B.J., et al., 2018. Prevalence and predictors of phthalate exposure in pregnant women in Charleston, SC. Chemosphere 193, 394-402. https://doi.org/10.1016/j.chemosphere.2017.11.019.

45. Werner E.F., Braun J.M., Yolton K., Khoury J.C., Lanphear B.P., 2015. The association between maternal urinary phthalate concentrations and blood pressure in pregnancy: The HOME Study. Environ. Health 14. https://doi.org/10.1186/s12940-015-0062-3.

46. Wu H., Kupsco A.J., Deierlein A.L., Just A.C., Calafat A.M., Oken E., et al., 2020. Trends and Patterns of Phthalates and Phthalate Alternatives Exposure in Pregnant Women from Mexico City during 2007-2010. Environ. Sci. Technol. 54, 1740-1749. https://doi.org/10.1021/acs.est.9b05836.

47. Yaghjyan L., Sites S., Ruan Y., Chang S., 2015. Associations of urinary phthalates with body mass index, waist circumference and serum lipids among females: National Health and Nutrition Examination Survey 1999-2004. Int. J. Obes. 39, 994-1000. https://doi.org/10.1038/ijo.2015.8.

48. Yang L., Yin W., Li P., Hu C., Hou J., Wang L., et al., 2021. Seasonal exposure to phthalates and inflammatory parameters: A pilot study with repeated measures. Ecotoxicol. Environ. Saf. 208, 111633. https://doi.org/10.1016/j.ecoenv.2020.111633.

49. Zhang Q., Lu X., Zhang X., Sun Y., Zhu D., Wang B., et al., 2013. Levels of phthalate esters in settled house dust from urban dwellings with young children in Nanjing, China. Atmos. Environ. 69, 258-264. https://doi.org/10.1016/j.atmosenv.2012.12.029.

50. Zhang X., Wang Q., Qiu T., Tang S., Li J., Giesy J.P., et al., 2019. PM2.5 bound phthalates in four metropolitan cities of China: Concentration, seasonal pattern and health risk via inhalation. Sci. Total Environ. 696, 133982. https://doi.org/10.1016/j.scitotenv.2019.133982.

51. Zhu Y., Wan Y., Li Y., Zhang B., Zhou A., Cai Z., et al., 2016. Free and total urinary phthalate metabolite concentrations among pregnant women from the Healthy Baby Cohort (HBC), China. Environ. Int. 88, 67-73. https://doi.org/10.1016/j.envint.2015.12.004.

52. Zong T., Lai L., Hu J., Guo M., Li M., Zhang L., et al., 2015. Maternal exposure to di-(2-ethylhexyl) phthalate disrupts placental growth and development in pregnant mice. J. Hazard. Mater. 297, 25-33. https://doi.org/10.1016/j.jhazmat.2015.04.065.

\section{Figures}




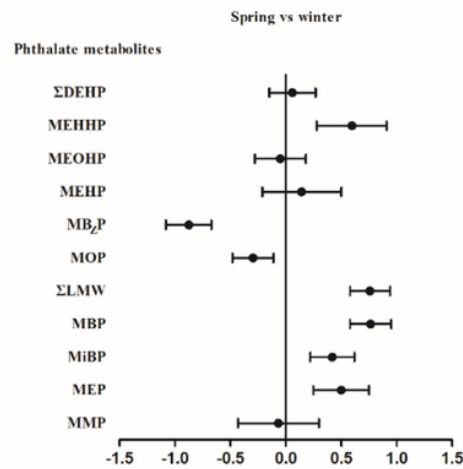

\begin{tabular}{cl}
$\beta(95 \% \mathrm{CI})$ & \multicolumn{1}{c}{$P$} \\
$0.06(-0.15,0.27)$ & 0.587 \\
$0.60(0.28,0.91)$ & $<0.001$ \\
$-0.05(-0.28,0.18)$ & 0.655 \\
$0.14(-0.21,0.50)$ & 0.438 \\
$-0.87(-1.08,-0.67)$ & $<0.001$ \\
$-0.30(-0.48,-0.11)$ & 0.002 \\
$0.76(0.58,0.94)$ & $<0.001$ \\
$0.77(0.58,0.95)$ & $<0.001$ \\
$0.42(0.22,0.62)$ & $<0.001$ \\
$0.50(0.25,0.75)$ & $<0.001$ \\
$-0.07(-0.43,0.30)$ & 0.718
\end{tabular}

Summer vs winter

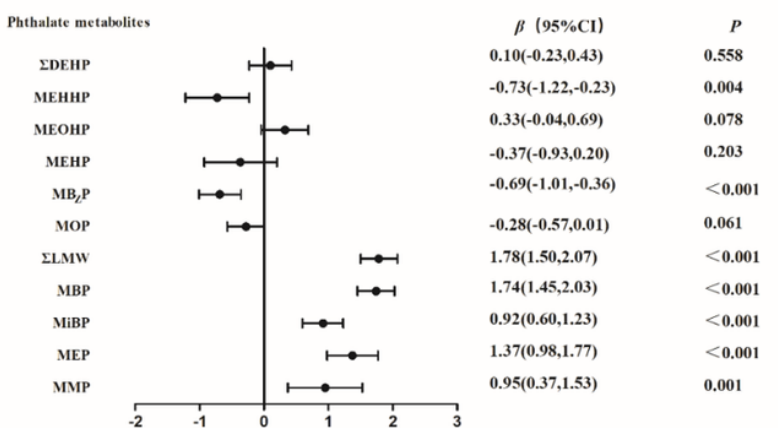

\begin{tabular}{|c|c|c|c|c|}
\hline \multicolumn{5}{|l|}{ Phubulus netrolies } \\
\hline Phthalate metabolites & & & $\beta(95 \% \mathrm{CI})$ & $P$ \\
\hline ЕDEHP & & $\bullet$ & $0.10(-0.12,0.32)$ & 0.384 \\
\hline МЕHНP & & $\longmapsto$ & $0.41(0.08,0.75)$ & 0.014 \\
\hline МЕОНР & $\longmapsto$ & & $-0.37(-0.62,-0.13)$ & 0.003 \\
\hline МEHP & $\mapsto$ & $\longrightarrow$ & $0.24(-0.14,0.62)$ & 0.215 \\
\hline $\mathrm{MB}_{2} \mathrm{P}$ & $\mapsto-1$ & & $-0.46(-0.68,-0.25)$ & $<0.001$ \\
\hline MOP & & $\mapsto$ & $0(-0.20,0.20)$ & 0.989 \\
\hline ELMW & & $\mapsto-1$ & $0.67(0.48,0.87)$ & $<0.001$ \\
\hline MBP & & $\mapsto-1$ & $0.66(0.46,0.85)$ & $<0.001$ \\
\hline MiBP & & $\mapsto$ & $0.53(0.32,0.74)$ & $<0.001$ \\
\hline MEP & & $\longmapsto$ & $0.70(0.44,0.97)$ & $<0.001$ \\
\hline MMP & & $\longmapsto$ & $0.93(0.54,1.32)$ & $<0.001$ \\
\hline-1 & 0 & 1 & & \\
\hline
\end{tabular}

\section{Figure 1}

Correlation between sampling season and phthalate metabolites

\section{Supplementary Files}

This is a list of supplementary files associated with this preprint. Click to download.

- Supplementarylnformation.docx 